\title{
Problems and Solutions Related to College
}

\author{
Students' Belief \\ Jinming Zhang \\ College of Humanities and Law, Tianjin Polytechnic University \\ Tianjin 300384, China
}

\begin{abstract}
With China staying in its social transition period, its changes in economy, politics and culture have influenced college students' thought to a large extent. Currently, in spite of the healthy and upward mainstream thought among college students, there are also some problems. This article elaborates on the problems and manifestations in college students' belief in different stages of college life, analyzes the causes and explores some solutions to them.
\end{abstract}

Keywords: College students, Belief, Solution

\section{Introduction}

Belief, a kind of spiritual pursuit at a higher level, converts ideal values into firm faith and then further dominates human thought and action. "Belief is the most fundamental and profound spiritual phenomenon in our human society, which will get expressed in all members following certain outlooks of world and life, values, and the supreme ideological form taking dominance over the others".

At present, China is undergoing the transitions from planned economy to market economy, from public society to mixed society, from leader-dominating society to constitutional one, from rural society to urban one, from poor society to wealthy one and from industrial society to information one, which offer us a lot of strategic opportunities, but bring about some problems as well. Besides promoting social development, such dramatic transitions have also exerted great influence on college students' thought.

\section{Problems and Manifestations in College Students' Belief}

\subsection{Problems and Manifestations in Freshmen's Belief}

Compared with others, freshmen have some incomparable characters: first, they are vigorous, energetic and ambitious. College, for them, is a place to cultivate themselves, to lead to success and to get into contact with other ambitious young men. Second, they have got good learning habits and attitudes. More than a decade of learning life, especially in senior high, has cultivated their good leaning habits, including learning a variety of things from different sources especially the library, attending classes punctually and attentively and respecting teachers and knowledge. As a result, most of them hold firm to the correct outlooks of world and life and values, believe in Marxist philosophy. All in all, their attitudes to life, including cognition and emotion, are correct and positive.

However, some problems may hide in such a good beginning. With sufficient leisure time in college life, those students strict with themselves will hold a positive attitude to their learning and life, however, those who lack self-discipline will kill their time in an empty way. Finding the college life boring, they are absorbed in online chatting, computer games all day long. As a result, their classes have to give way to these meaningless things. Actually, not the life, but these students themselves create their degradation (Lijie Chen, 2005). Just as what a sentence popular with college students nowadays says, "although degradation is guilty, it is beautiful". If these problems remain untouched, what is awaiting us is worse condition in sophomores and juniors.

\subsection{Problems and Manifestations in Sophomores and Juniors'Belief}

Sophomores and juniors take great efforts to collect all kinds of material from the library and the Internet instead of only learning from their teachers. In this period, they put more importance on self-learning and a variety of theories and opinions. Those students with positive outlooks of world and life and correct values will pay more attention to colorful social life, international situations, national policies as well as some events in and outside China, hence expanding their knowledge at the macro level. On the contrary, those students who began to fool along in the first year suffer from spiritual weakness, which is expressed in the lack in interest, concern about things and positive attitudes to life (Junxia Zhang, 2007). Instead of absorbing themselves to online chatting or computer games, they begin to puff those opinions they think right and prefer those odd theories. Boys care for those extreme views while girls are more fond of 
constellation theories, fortune-telling and love and so on. They aren't worried about drinking, fighting, their empty college life, not to mention failing in the examination.

Obviously, without strengthened supervision and guidance of school authorities, these students will suffer from ideological myths and great damage, even violate the law and do harm to our society although they are just exceptions. Luckily, most of them will go through their senior life and get into the society finally.

\subsection{Problems and Manifestations in Seniors'Belief}

The last year in college life is filled with hardship for most college students, during which they have to transfer from their student life to vocational one and therefore, are faced with complicated decisions and reflections about their future jobs, graduation examination, thesis oral defense, their future with their lovers, hence suffering from great psychological pressure and conflicts. Of course, most students have obtained correct world outlook, life outlook and values as well as rich knowledge and can adjust themselves psychologically. However, some others may suffer from psychological problems resulting from defects in study or job hunting. As a result, they may lose their hope for their own future as well as the whole society and turn to money worship or formalism instead. Reflected in behavior, they may damage public properties, fight against others or do some other improper things. What's worse, those serious ones will hate the whole society.

With their special social status, increasing knowledge and skills, establishment of their self-confidence, stronger independence, senior students try to break away from the exterior restriction and interference and hope to decide on their own fate. Therefore, they have strong self-respect, react violently to criticisms and tend to go to extreme in their views about some negative things existing in the current society.

\section{Causes of the Problems in College Students' Belief}

\subsection{Subjective Factors}

College students lie in the stage of transferring from childhood to adulthood physically as well as learning to be independent psychologically. Therefore, they have relatively poor cognitive and thinking abilities, hence producing partial opinions about some issues; they are vigorous, energetic and care for new things, including those doubting, criticizing and rejecting the traditional ones, hence having impulsive emotion and psychological states. In addition, influenced by market economy, some students turn to money worship and hedonism. So, when they are faced with a variety of information resources, they tend to feel at loss and then make wrong decisions, which will force them to doubt their former belief, shake it and then end up with wrong one.

\subsection{Objective Factors}

\subsubsection{Drawbacks in Higher Education}

Since Chinese college students spend most of their college life in school, the educational system, pattern and culture have great influence on their outlooks of world and life and their values. First, college teachers' theoretical and teaching capacity influences students' moral quality. Some teachers, only paying attention to their teaching tasks while neglecting to communicate with them, fail to learn about their life and belief; some, neglecting college students' psychological endurance, tell too much about the seamy side of our society, which will result in students' extreme understanding about some issues. Second, school regulations also have profound influence on college students' thinking and morality. Currently, most colleges put much importance on students' academic and practical performance while neglecting to cultivate their personality and characters. In addition, in most college students' minds, college stands for justice, fairness and humanity, which calls for our schools to strengthen their institutional construction to eliminate malpractice on campus and those regulations with poor efficiency.

\subsubsection{Negative Influences in Social Environment}

The transition of Chinese society has not only offered some strategic opportunities but also caused some problems. As a result, there must be some conflicts in the course of building a well-to-do society throughout the country and establishing a harmonious socialist society.

As for political structure, some problems, such as slack work, low efficiency, non-public government affairs and lack in regulations an so on, have degraded the authority and destroyed the image of government in people's minds. Besides, there are corruptions and disordered competitions in government, Communist Party itself, schools and enterprises, which have led to students' opinion that the current society is a money-oriented one and corruption is just a common behavior. In addition, "people are increasingly worried and disappointed at the issues in education, medical treatment and housing. For college students, when they are confronted with great pressure in employment and living competition, the great contrast between their ideal and the reality, between school education and social practice, their belief tend to be destroyed in an instant." (Linli Tang, 2007) Finally, in the aspect of culture, two-thousand-year feudal society in China's history has planted superstition into Chinese people's minds. Just as someone says, Chinese people have no belief and they will try everything coming to them when they really need something. Therefore, the popularity of 
Internet has resulted in people's narrower ways of thinking and more superficial thinking as well as their poorer abilities to reflect on and explore into those deep-level issues. Influenced by it, college students begin to believe in western culture, such as constellation and Tarot as well as traditional Chinese culture, such as geomantic omen and temples.

\section{Solutions to the Problems in College Students' beliefs}

In 1988, it was mentioned in a report issued by Japan Temporary Education Committee that it was urgent to strengthen the moral education in school since it was critical for Japan's future whether the youth in Japan could be cultivated to be qualified in morality and creativity for the future $21^{\text {st }}$ century. In addition, it pointed out that as the central institution of moral education, schools are expected to conduct their education in a multi-dimensional and multi-level way instead of inputting knowledge and skills one way into students (Huifang Chen). In terms of the important role of schools, this article will focus on the solutions available in school education to the above problems.

\subsection{Conducting Belief Education through Curriculum Setting}

After the reform in the courses of ideological and political theories in Chinese colleges, Marxist contents have been perfected and enriched to exert its influence in college students' action. Under current circumstances, these theories should be connected with students' ideology and life as well as the reality of Chinese society. In addition, we should face up to some problems in our reality and help students to form a correct understanding about a series of unfavorable things in China's development, to distinguish phenomenon from nature, principal from non-principal contradictions and to strengthen the core values of socialism with Chinese characteristics taking their physical and psychological ages into consideration.

As for freshmen, we should encourage them to hold positive attitudes and opinions. We should help them to get familiar with the new environment, blend in with others in their school life. In addition, help should be offered in their knowledge about the characteristics of their majors, the potential employment outlook and the right way to study and live their life during the coming four years. Only by solving their problems in a practical way will they form and hold firm to correct values and outlooks of world and life. When it comes to sophomores and juniors, efforts should be made to establish correct system of viewing and solving problems, especially to from the right view about the Internet, which will enable them to use it not be addicted to it. Besides, if they establish right views about love under proper instructions, they'll be able to support each other in study. And for senior students, right views of employment seem particularly important, which will help them to conquer their emotional disorder, lack of confidence and hesitation about their job orientation.

\subsection{Strengthening the Cultural Construction on Campus}

Just as someone says, children are surrounded by potential socialization of politics wherever they are. Therefore, schools are expected to put more importance on the construction of their cultural atmosphere. Since the setting of a school's overall environment, its atmosphere and interpersonal relationship can be experienced personally, they are more likely to be accepted by students emotionally and ideologically. Actually, this kind of influence is not imperative but conducted in an unconscious way.

First, some good civic awareness and conduct regulations should be displayed to freshmen to inform them of the importance to cultivate their morality in addition to learning knowledge at college. Besides, educators and those educated should be put to an equal position, their communication should be enhanced and students' dominance and importance should be exerted in their moral judgment and values choices. Those junior and senior students should be encouraged to organize all kinds of community activities, such as part-time Party School, the Communist Youth League School, groups to study the latest theoretical achievements of Chinese Marxism and so on. In this way, students from different grades will get together to study some important theories such as that of socialism with Chinese characteristics to form right values, outlooks of world and life in their minds. In addition, we can manage to establish healthy and active cultural atmosphere on campus by organizing interest groups, cultural activities and some volunteer communities. Seniors should be organized to take part in social practice and labor practice to improve their abilities in dealing with problems in practice and adapting themselves to society and to form their practical values from the plainest work and life instead of nihilism and fickleness presented on the Internet.

As the great poet Johann Wolfgang von Goethe says, the unique theme of world history lies in the conflicts between belief and disbelief. All those belief-dominating ages have produced splendid and long-lasting achievements for their generation and their offspring whatever form is adopted in their belief, while those disbelief-dominating ages have only ended up with a few achievements whatever form is adopted. Even if the latter boasts about a kind of false glory, it will fly away in an instant because nobody will bother to know anything about disbelief. Similarly, belief is of great significance for China and the whole human history. Chinese college students are the constructer and successor of the cause of socialism with Chinese characteristics, whose belief is closely related to the stability and development of China. Consequently, great efforts are supposed to be made to solve the current problems in their belief and promote their healthy development. 


\section{References}

Chen, Huifang. The Means of Ideological and Political Education in Western Nations and the Inspiration. [Online]: http://www.gotoread.com/article/?MagID=4856\&wid=96010.

Chen, Lijie. (2005). Belief Crisis among Contemporary College Students and Its Reconstruction. Liaoning Education Research. 12.

Shao, Yingxia., Bi, Lina. \& Zhao, Yan. Belief Crisis among Contemporary College Students and Its Reconstruction. Basic Theory Research.

Tang, Linli. (2007) The Realistic Manifestation of College Students'Belief Crisis in Internet Age. Materials of Science and Education. Early August 2007.

Zhang, Junxia., Xing, Lingguo. \& Guo, fuyan. (2007). On the Cause of the Belief Crisis of College Students and the Countermeasure. Journal of Changsha University. Vol 21. July 2007. 